\title{
Bilateral Nephrectomy as a Rescue Therapy for Hemodialyzed Patient with Malignant Hypertension - Case Report
}

\author{
Lucian Stefan Macsim $^{\mathrm{a}}$ Paweł Stróżecki $^{\mathrm{b}}$ \\ Ilona Miśkowiec-Wiśniewska ${ }^{\text {b, c }}$ Anna Kardymowicz ${ }^{b}$ \\ Jacek Manitius ${ }^{\text {b }}$ \\ ${ }^{a}$ Student in International Erasmus Exchange Programme (2010-2011), \\ University of Medicine and Pharmacy, Iasi, Romania; Departments of \\ ${ }^{b}$ Nephrology, Hypertension and Internal Diseases, and ${ }^{\mathrm{C}}$ Hygiene and \\ Epidemiology, Nicolaus Copernicus University of Toruń, Collegium Medicum, \\ Bydgoszcz, Poland
}

\section{Key Words}

Bilateral nephrectomy · Chronic kidney disease $\cdot$ Hemodialysis · Malignant hypertension

\begin{abstract}
We present the case of a 64-year-old male patient in whom malignant phase of hypertension developed during dialysis therapy. Hypertension was resistant to pharmacological therapy with seven antihypertensive drugs and dialysis therapy with ultrafiltration. In this patient bilateral nephrectomy was performed as a rescue therapy. It led to better control of blood pressure and allowed to reduce the number and dosage of antihypertensive medications.
\end{abstract}

\section{Introduction}

Malignant hypertension (MHT) is quite a rare condition, which occurs in $<1 \%$ of people with high blood pressure, including both, children and adults [1]. MHT is characterized by a sudden and rapid development of extremely high blood pressure, but the true hallmark of MHT is fibrinoid arteriolar necrosis in many vascular beds. 
MHT is usually defined clinically as severe hypertension together with bilateral retinal hemorrhages and exudates, with or without papilledema on fundoscopy [1]. It is more common in younger adults, especially African-American men. It also occurs in women with toxemia of pregnancy, and patients with kidney disorders or collagen vascular disorders. Demography and the number of new cases of MHT have not changed dramatically over the past 40 years $[1,2]$.

Five-year post-MHT survival has improved significantly over the last decades, possibly related to lower blood pressure targets, tighter blood pressure control, and availability of new classes of antihypertensive drugs [1]. There have been reports that some groups of patients with MHT caused by chronic kidney disease are resistant to antihypertensive drugs and even to chronic ultrafiltration [3]. For these patients it was proposed that bilateral nephrectomy followed by hemodialysis is a successful method of decreasing and controlling the blood pressure levels [3, 4].

\section{Case Report}

We present the case of a 64-year-old dialyzed male patient with history of hypertension from about 25 years. The diagnosis of chronic kidney disease was established in November 2004 when the patient was admitted to nephrology outpatient clinic with a high level of creatinine $-4.3 \mathrm{mg} / \mathrm{dl}$, and proteinuria $110 \mathrm{mg} / \mathrm{dl}$. The patient was in good general condition, with blood pressure value of $130 / 80 \mathrm{~mm} \mathrm{Hg}$. Ultrasound abdominal examination showed small kidneys: right $75 \times 45 \mathrm{~mm}$, and left $95 \times 50 \mathrm{~mm}$. Doppler examination did not reveal features of renal artery stenosis. Fundoscopic examination showed grade II hypertonic angiopathy according to the Keith-Wagener classification. At that moment, the patient was treated with nitredipine $(2 \times 20 \mathrm{mg} /$ day $)$, doxazosin ( $4 \mathrm{mg} /$ day $)$, atenolol (25 mg/day), torasemide (10 mg/day), and allopurinol (100 mg/day).

In the years 2005-2006, a progression of chronic kidney disease and worsening of blood pressure control $(170 / 100 \mathrm{~mm} \mathrm{Hg})$ were observed. As the glomerular filtration rate (eGFR) decreased $<15$ $\mathrm{ml} / \mathrm{min} / 1.73 \mathrm{~m}^{2}$, in June 2006, Tenckhoff catheter was inserted, and the patient started peritoneal dialysis (PD). In laboratory tests, anemia was found, with a hemoglobin level of $10.3 \mathrm{~g} / \mathrm{dl}$, and treatment with iron supplementation and folic acid was started.

In 2007, the patient underwent coronary angiography due to unstable angina, and coronary angioplasty (PTCA) with stent insertion to right coronary artery was performed. In 2008, due to dialysis catheter obstruction, omentectomy was performed. In June 2008, the patient underwent cholecystectomy and was temporarily switched to hemodialysis. On hemodialysis therapy, the dry weight was decreased by $7 \mathrm{~kg}$. After new Tenckhoff catheter insertion, the patient started PD again in September 2008. At the same time, hypothyreosis was diagnosed, and levothyroxine therapy was started.

In November 2008, the patient was admitted to the hospital due to a significant high blood pressure level $(210 / 110 \mathrm{~mm} \mathrm{Hg})$, severe anemia $(6.6 \mathrm{~g} / \mathrm{dl})$ and thrombocytopenia $\left(66,000 / \mathrm{mm}^{3}\right)$. Fundoscopy revealed hypertensive bilateral retinal hemorrhages, exudates and papilledema. Echocardiography revealed left atrium enlargement, left ventricular hypertrophy, and left ventricular ejection fraction of 55\%. In 24-hour blood pressure monitoring (ABPM), the mean value was 199/109 $\mathrm{mm} \mathrm{Hg}$, and nondipper pattern of blood pressure was found. Bone marrow biopsy was performed, but the results were within normal limits. Due to worsening of blood pressure control, Doppler examination and subsequently renal artery angio-CT were performed, in which $50 \%$ stenosis of left renal artery was shown. Antihypertensive medication was changed to: ramipril $10 \mathrm{mg}$, telmisartan 80 $\mathrm{mg}$, bisoprolol $5 \mathrm{mg}$, doxazosin $6 \mathrm{mg} /$ day, methyldopa $750 \mathrm{mg} /$ day, dihydralazine $75 \mathrm{mg} /$ day, eplerenone $25 \mathrm{mg} /$ day, and ultrafiltration was increased to reduce dry weight. The concomitant medication involved: acetylosalicylic acid $75 \mathrm{mg}$, clopidogrel $75 \mathrm{mg}$, simvastatin $20 \mathrm{mg} / \mathrm{day}$, omeprazole $20 \mathrm{mg} /$ day, levotyroxine $100 \mu \mathrm{g} /$ day, and calcium carbonate $6 \mathrm{~g} / \mathrm{day}$. The patient received 8 red blood cell (RBC) units, and after the stabilization of blood pressure, erythropoietinstimulating agent (ESA) (Epoetinum Beta $3 \times 2,000 \mathrm{IU}$ s.c./week) was added to correct the anemia. A better blood pressure control was obtained with ABPM values of 167/90 mm Hg during day and $171 / 91 \mathrm{~mm} \mathrm{Hg}$ at night. Spontaneous platelet count increase to $114,000 / \mathrm{mm}^{3}$ was observed. 
In February 2009, the patient was admitted to the hospital due to headache and blood pressure of 240/140 mm Hg despite antihypertensive therapy with 7 drugs. Fundoscopy confirmed presence of bilateral neuroretinopathy with papilledema. ESA therapy was stopped, and ultrafiltration during dialysis was increased. Subsequent ABPM showed mean blood pressure 164/91 mm Hg with nondipper pattern, and fundoscopy performed in July 2009 revealed grade II hypertensive angiopathy.

In August 2009, the patient was treated due to the symptoms of PD-related peritonitis, with Escherichia coli in peritoneal fluid culture. After therapy with ceftazidime, negative peritoneal fluid cultures were obtained, but PD adequacy significantly decreased and symptoms of malnutrition occurred. Due to this, the decision was made to change the dialysis modality, arteriovenous fistula was created, and the patient started hemodialysis therapy in October 2009 in another dialysis center.

In November 2009, the patient presented with high blood pressure of 210/110 mm Hg and symptoms of heart failure despite antihypertensive therapy with 7 antihypertensive drugs. Fundus examination again showed neuroretinopathy with papilledema. Brain CT scan was performed to exclude intracranial bleeding or mass. Intravenous antihypertensive therapy with nitroglycerine and urapidilum was used, and ultrafiltration was increased to reduce dry weight. Subsequently, therapy with oral antihypertensive drugs was modified, and the patient received: quinaprilum $2 \times 40 \mathrm{mg} / \mathrm{day}$, telmisartan $80 \mathrm{mg} /$ day, amlodypine $2 \times 10 \mathrm{mg} /$ day, bisoprolol $5 \mathrm{mg} /$ day, doxazosin $4+8 \mathrm{mg} /$ day, methyldopa $3 \times 500 \mathrm{mg} /$ day, and eplerenone $50 \mathrm{mg} /$ day. Despite this therapy, blood pressure was still high $(190 / 110 \mathrm{~mm} \mathrm{Hg})$ and the decision was made to perform bilateral nephrectomy as a rescue therapy for MHT.

A simultaneous bilateral nephrectomy was performed in the Department of Urology of the Jurasz University Hospital, Bydgoszcz, Poland. After the operation, the patient required therapy in the Intensive Care Unit due to postoperative respiratory insufficiency. In early postoperative course, everyday hemodialysis was performed due to features of hypervolemia with decrease of dry weight from 74 to $67 \mathrm{~kg}$. Lowering of blood pressure to 130/70-140/80 mm Hg was observed. In further course, the antihypertensive therapy was gradually reduced. ESA therapy was started again with no blood pressure increase during ESA administration.

Six months after bilateral nephrectomy, therapy involved 3 hemodialysis sessions per week and antihypertensive medication as follows: quinaprilum $20 \mathrm{mg}$ /day, amlodipine $5 \mathrm{mg}$ /day, bisoprolol 5 $\mathrm{mg} /$ day, telmisartan $40 \mathrm{mg} /$ day. Concomitant medication involved: acetylsalicylic acid $75 \mathrm{mg} / \mathrm{day}$, pantaprazolum $20 \mathrm{mg} /$ day, levothyroxine $125 \mu \mathrm{g} /$ day, and atorvastatin $10 \mathrm{mg} /$ day. In February 2011, the patient was placed on waiting list for kidney transplantation and in June 2011, the patient underwent kidney transplantation.

\section{Discussion}

Nowadays MHT is quite a rare condition, but being a rapid progressive disorder, it leads to irreversible vascular changes and dangerous complications when is not treated correctly and fast enough. MHT is defined as severe hypertension that occurs along with vascular complications such as retinal hemorrhages and exudates, with or without papilledema on fundoscopy $[1,5]$. All the major organs are at risk from the severe blood pressure elevations present in MHT, but the kidneys, eyes, and brain appear to be at highest risk. Also microangiopathic hemolytic anemia may occur in the course of MHT. In the past, when antihypertensive therapy was not freely available, MHT resulted in death within a year in over $90 \%$ of patients as a result of end organ damage or renal failure [6, 7]. The prognosis of MHT has improved over the last decades thanks to the new pharmacological therapies, hemodialysis and even surgery $[1,7]$. Five-year survival increased from $32 \%$ prior to 1977 to $91 \%$ for patients diagnosed between 1977 and 2007 [1]. 
In epidemiological studies, about 23\% of MHT was related to chronic kidney disease [1]. In chronic kidney disease, there are a lot of factors that contributes to hypertension, such as sodium retention, total body volume expansion, hyperactivity of the renin-angiotensin-aldosterone system (RAAS), an increased activity of sympathetic nervous system and nitric oxide deficiency [8].

Despite availability of new classes of antihypertensive drugs and volume control with dialysis therapy, MHT may occur in dialyzed patient. In such cases, when blood pressure is not well controlled using pharmacotherapy and ultrafiltration, bilateral nephrectomy might be the rescue therapy for malignant phase of hypertension. It was also shown in other studies that in MHT, bilateral nephrectomy and renal transplantation facilitates a better control of blood pressure, prolongs survival, and allows a better rehabilitation [5, 9-11].

\section{Conclusions}

The present case report shows that in dialyzed patients with malignant stage hypertension resistant to pharmacological therapy, bilateral nephrectomy might be a rescue therapy to improve the control of blood pressure.

\section{Acknowledgements}

I thank Professor Jacek Manitius, MD, PhD, Head of Department of Nephrology, Paweł Stróżecki, MD, Ilona Miśkowiec-Wiśniewska, MD, for allowing me to do this study and for their continued support throughout this research and for the generosity to provide all the necessary data.

The study was partially founded by Fundacja Nerkadar na Rzecz Zapobiegania i Leczenia Chorób Nerek.

\section{References}

1 Lane DA, Lip GY, Beevers DG: Improving survival of malignant hypertension patients over 40 years. Am J Hypertens 2009;22:1199.

2 http://www.healthline.com/adamcontent/malignant-hypertension.

-3 Onesti G, Swartz C, Ramirez O, et al: Bilateral nephrectomy for control of hypertension in uremia. $\operatorname{Tr} \mathrm{Am}$ Soc Artif Int Organs 1968;14:361.

4 Rubini ME, Koppel M, Shinaberger JH, Cobourn JW, Sokol A: Definitive treatment of malignant hypertension. Presented at Second Annual Meeting of American Society of Nephrology, Washington, DC, November 23-25, 1968.

5 Cruz C, Callender CO, Cummings Y, et al: Malignant hypertension revisited: the role of bilatera nephrectomy. J Natl Med Assoc 1980;72:453.

-6 González R, Morales E, Segura J, et al: Long-term renal survival in malignant hypertension. Nephrol Dial Transplant 2010;25:3266.

7 Long-term therapy and prognosis of malignant hypertension. Can Med Assoc J 1960;83:127.

8 Campese V, Ku E, Park E: Sympathetic renal innervation and resistant hypertension. Int J Hypertens 2011;2011:814354.

9 Medina A, Bell PR, Briggs JD, et al: Changes of blood pressure, renin, and angiotensin after bilateral nephrectomy in patients with chronic renal failure. Br Med J 1972;v.4:5842.

10 Hampers CL, Skillman JJ, Lyons JH, et al: A hemodynamic evaluation of bilateral nephrectomy and hemodialysis in hypertensive man. Circulation 1967;35:272.

11 El-Said WM: Bilateral nephrectomy as a treatment of malignant hypertension. Int Urol Nephrol 1974;6:209. 